\title{
CEREBRAL COMPENSATION FOR CHRONIC NORADRENERGIC DENERVATION INDUCED BY LOCUS CERULEUS LESION: RECOVERY OF RECEPTOR BINDING, ISOPROTERENOL-INDUCED ADENYLATE CYCLASE ACTIVITY, AND OXIDATIVE METABOLISM ${ }^{1}$
}

\author{
SAMI I. HARIK, R. BRADFORD DUCKROW, JOSEPH C. LAMANNA, MYRON ROSENTHAL, \\ VIRENDRA K. SHARMA, AND SHAILESH P. BANERJEE \\ Department of Neurology, University of Miami School of Medicine, Miami, Florida 33101 and Department of Pharmacology and Toxicology, \\ University of Rochester School of Medicine and Dentistry, Rochester, New York 14642
}

\begin{abstract}
The long term effects of specific noradrenergic denervation of rat cerebral cortex were considered in parallel studies of in vilro noradrenergic receptor binding and isoproterenol-induced adenosine 3': $5^{\prime}$-monophosphate (cyclic AMP) generation and of in vivo oxidative metabolism. Noradrenergic denervation was achieved by the local, unilateral injection of 6-hydroxydopamine into the locus ceruleus. Cerebral noradrenaline remained depleted throughout the 8-week duration of the study. Ligand-binding assays showed increased $\beta$-adrenergic receptors 2 weeks after locus ceruleus lesion with recovery occurring by 4 weeks. There were no changes in $\alpha_{1}$-adrenergic receptors. Isoproterenolinduced cyclic AMP generation increased at 2 weeks after lesion but recovered at 8 weeks. Dual wavelength reflection spectrophotometric measurements of cytochrome oxidase reduction/oxidation and local blood volume shifts, provoked in situ by direct cortical stimulation, also demonstrated abnormalities at 2 weeks with recovery by 4 weeks after lesion. Thus, in vivo and in vitro changes after locus ceruleus lesion are reversible and the time course of these changes is related temporally. These data suggest that cerebral cortex has adaptive capabilities which are activated to compensate for prolonged noradrenaline depletion. We also speculate that there may be a causal relationship between the in vitro and in vivo parameters studied.
\end{abstract}

Changes in organ systems caused by interruption of their neuronal input have attracted attention for at least a century (Cannon and Rosenblueth, 1949). Most studies have concerned the autonomic nervous system or denervation effects on skeletal muscles. These studies gave rise to the concept that an organ deprived of neural input becomes more sensitive to the absent neurotransmitterthe phenomenon of denervation supersensitivity. Mechanisms underlying denervation supersensitivity have been proposed for peripheral cholinergic and adrenergic systems. Cholinergic denervation supersensitivity has been associated with an increase in the number of postsynaptic receptors (Miledi and Potter, 1971; Berg et al., 1972), while adrenergic denervation supersensitivity involves decreased presynaptic inactivation of noradrenaline (NA) (Trendelenburg, 1966) as well as a postsynaptic increase in the number of receptor sites (Pointon and Banerjee, 1979).

In the central nervous system, the complexity of interactions among many neurotransmitters has made inves-

This work was supported by Public Health Service Grants NS16617, NS14325, NS14319, NS05820, and HL18185. J. C. L. is the recipient of Research Career Development Award NS00399. tigations of denervation effects more difficult. Nevertheless, decreased noradrenergic activity resulted in increased isoproterenol-induced adenosine $3^{\prime}: 5^{\prime}$-monophosphate (cyclic AMP) generation (Palmer et al., 1973; Dismukes et al., 1975, 1976; Sporn et al., 1977; Skolnick et al., 1978; Dolphin et al., 1979) and an increased number of $\beta$-adrenergic receptor sites in the cerebral cortex (Sporn et al., 1977; Jonsson and Hallman, 1978; Skolnick et al., 1978; Dolphin et al., 1979; Sharma et al., 1979, 1981). A complication in interpreting the results of most of these studies is that depletion of cerebral NA was produced by nonspecific means, such as by the systemic administration of reserpine or by intraventricular 6-hydroxydopamine (6-OHDA). Also, the long term effects of denervation and the possibility of recovery were not well documented.

In this report, we consider the acute and chronic effects of specific interruption of the noradrenergic innervation of rat cerebral cortex on three parameters previously shown to be affected by such denervation: (1) adrenergic receptor binding to particulate fractions of the cerebral cortex, (2) isoproterenol-induced increase in adenylate cyclase activity in cortical slices, and (3) oxidative metabolic activity of the cerebral cortex studied in situ in 
response to electrical stimulation. The noradrenergic input to the cerebral cortex was interrupted by selective chemical lesion of the nucleus locus ceruleus (LC) by local microinjection of 6-OHDA. This work follows from previous studies which demonstrated that changes in each of the three parameters occur 2 weeks following such LC lesion (Harik et al., 1979a; LaManna et al., 1981; Sharma et al., 1981). We show here that these changes are transient despite the persistence of cerebral NA depletion. We conclude that compensatory capabilities are present in the cerebral cortex and result in adaptation to the chronic loss of NA.

A preliminary communication of these data has been presented (Harik et al., 1979b).

\section{Materials and Methods}

Animals. Adult male Wistar rats, weighing 175 to 250 gm at the time of LC lesion, were used in all experiments. Rats were housed (four per cage) under diurnal light conditions with unlimited access to food and water. They were allowed a minimum of 5 days of acclimation before LC lesions or sham operations were undertaken.

$L C$ lesion. The LC was lesioned by the local stereotaxic microinjection of $6 \mu \mathrm{g}$ of $6-\mathrm{OHDA}$ dissolved in $3 \mu \mathrm{l}$ of $0.9 \% \mathrm{NaCl}$ solution containing $1 \mathrm{mg} / \mathrm{ml}$ of ascorbic acid and adjusted to $\mathrm{pH}$ 5.5. Details of the lesion procedure have been reported previously (LaManna et al., 1981; Sharma et al., 1981). The LC lesions were made unilaterally with equal distribution between left and right sides. Control animals were sham operated, but there was no infusion into the LC. In preliminary experiments, the infusion of vehicle solution (ascorbic acid in $0.9 \% \mathrm{NaCl}$ ) into the LC did not result in significant alterations of cerebral NA content.

After LC lesion, rats were returned to their cages for periods of 1 to 8 weeks before further experimentation. Separate groups of rats were used to test the effect of cortical NA depletion on each of the three specific parameters considered in the introduction. In all rats, tissue samples (about $25 \mathrm{mg}$ ) were obtained from each parietal cortex at the end of each experiment. The samples were frozen immediately in liquid nitrogen and stored at $-40^{\circ} \mathrm{C}$ until assayed for NA content. Except for rats used 1 week after LC lesions, the efficacy of the LC lesion was assessed by the degree of NA depletion that it produced in the ipsilateral cerebral cortex. LC lesions were considered successful when NA was depleted by a minimum of $70 \%$ in comparison to the NA content of the contralateral cerebral cortex. Mean NA depletion was more than $90 \%$ (Fig. 1). This criterion could not be applied to assess lesion success in rats killed 1 week after 6-OHDA injection since our data showed that cortical NA depletion is incomplete after this short interval (Fig. 1). However, because of the high "success" rate of LC lesions (80 to $90 \%$ when NA was assayed 2 weeks or longer after 6OHDA injection), it was assumed that all rats used in experiments 1 week after LC lesion were lesioned successfully.

Only data obtained from successfully lesioned and control rats were used in subsequent analyses. Data from NA-depleted ipsilateral cerebral hemispheres were compared to that from contralateral hemispheres and from controls.
Adrenergic receptor binding. At intervals of 1 to 8 weeks after unilateral LC lesion or sham operation, rats were killed by decapitation and the cerebral cortical mantles were quickly dissected bilaterally. A small sample was taken from each parietal cortex for NA analysis and the rest of the cerebral cortex was used for receptor binding assays.

$\alpha_{1}$ - and $\beta$-adrenergic receptor binding were assayed in individual cortical samples by methods previously described (Sharma et al., 1981). [ $\left.{ }^{3} \mathrm{H}\right] \mathrm{WB}-4101(25.4 \mathrm{Ci} /$ mmol) and $\left[{ }^{3} \mathrm{H}\right]$ dihydroalprenolol (DHA) $(49 \mathrm{Ci} / \mathrm{mmol})$ were used as ligands since they have been shown to identify $\alpha_{1}$ - and $\beta$-adrenergic receptor sites in rat brain (Bylund and Snyder, 1976; Greenberg et al., 1976; U'Prichard et al., 1977). In brief, the tissues were thawed on ice and homogenized in 20 vol of $0.05 \mathrm{M}$ Tris (tris(hydroxymethyl)aminomethane) buffer, $\mathrm{pH} 7.4$, in a Brinkmann Polytron and centrifuged at $49,000 \times g$ for 15 min. All procedures were carried out at 0 to $4^{\circ} \mathrm{C}$ unless stated otherwise. The pellet was washed twice and then suspended in 100 vol of the Tris buffer. The volume of the binding assay was $1 \mathrm{ml}$, including about $1 \mathrm{mg}$ of tissue protein which was incubated with the appropriate tritiated ligand for $20 \mathrm{~min}$ at $25^{\circ} \mathrm{C}$. Only one concentration of the ligand was used in these experiments $(2.5 \mathrm{~nm}$ for WB-4101 and 1.0 nM for DHA). This was because the amount of tissue from each hemisphere was insufficient for kinetic analysis of binding. Also, Scatchard kinetic analyses for the affinity of hinding and the maximal number of binding sites for WB-4101 and DHA have been reported in NA-depleted cortical tissue pooled from rats 2 weeks after LC lesion (Sharma et al., 1981). At the end of the incubation, the reaction mixture was filtered under reduced pressure through glass fiber filters and rinsed four times with $4-\mathrm{ml}$ volumes of ice cold Tris buffer. The filters were dried and their tritium content was assayed in a liquid scintillation spectrometer at approximately $30 \%$ efficiency.

Corrections were made for nonspecific binding determined by measuring tritiated ligand binding in parallel incubations that contained excess NA (0.1 mM). Specific binding, defined as the difference between total and nonspecific binding, was about $70 \%$ of the total binding. All assays were done in triplicate with less than $5 \%$ interassay variation. The results were expressed in femtomoles of ligand bound per $\mathrm{mg}$ of tissue protein. Protein was assayed by the method of Lowry et al. (1951).

Isoproterenol-induced cyclic AMP generation. Two and 8 weeks after unilateral LC lesions or sham operation, rats were killed by decapitation, the brains were dissected quickly, and the meninges were removed carefully. Samples were taken from each parietal cortex for NA determination to ascertain the efficacy of the LC lesion. Cortical slices of 1-mm thickness were immersed in ice cold Krebs-Ringer buffer $(\mathrm{NaCl}, 124 \mathrm{mM}$; $\mathrm{KCl}, 4.7 \mathrm{mM}$; $\mathrm{MgSO}_{4}, 1.2 \mathrm{~mm} ; \mathrm{NaHCO}_{3}, 24.8 \mathrm{~mm} ; \mathrm{NaH}_{2} \mathrm{PO}_{4}, 1 \mathrm{~mm}$; $\mathrm{CaCl}_{2}, 0.75 \mathrm{~mm}$; glucose, $6.5 \mathrm{~mm}$; freshly prepared and gassed with a mixture of $95 \% \mathrm{O}_{2}$ and $5 \% \mathrm{CO}_{2}, \mathrm{pH} 7.4$ ) and then diced with a McIlwain tissue chopper to yield minces of $1 \times 0.4 \times 0.4 \mathrm{~mm}$. Minces from each hemisphere were suspended in $20 \mathrm{ml}$ of oxygenated Krebs-Ringer buffer and incubated in a shaking water bath at $37^{\circ} \mathrm{C}$ under an atmosphere of $95 \% \mathrm{O}_{2}$ and $5 \% \mathrm{CO}_{2}$. After $1 \mathrm{hr}$, 
the buffer was discarded by aspiration and portions of the minces (about $1 \mathrm{mg}$ of tissue protein) were re-incubated under the same conditions in $5 \mathrm{ml}$ of modified Krebs-Ringer buffer (containing 1 mM 3-isobutyl-1methyl xanthine) in the presence or absence of $0.1 \mathrm{~mm} l$ isoproterenol. After $15 \mathrm{~min}$ of incubation at $37^{\circ} \mathrm{C}$, the reaction was stopped by immediate cooling in an ice bath. The buffer was aspirated and the minces were homogenized in $3 \%$ perchloric acid. Cyclic AMP content of the minces was assayed in aliquots of the supernatant in duplicate, utilizing the protein-binding assay of Gilman (1970) as provided commercially by Diagnostic Products Corp. The perchloric acid precipitate was solubilized in $1 \mathrm{~N} \mathrm{NaOH}$ and assayed for its protein content (Lowry et al., 1951). Four tissue samples obtained from each hemisphere were assayed for cyclic AMP generation, two under basal conditions and two after addition of $0.1 \mathrm{~mm}$ isoproterenol. Cyclic AMP generation was expressed as picomoles per $\mathrm{mg}$ of protein per $15 \mathrm{~min}$.

Cerebral oxidative metabolism in situ. A third group of rats was prepared for oxidative metabolic studies 1 to 8 weeks after unilateral LC lesion. Details of the surgical and recording procedures have been described (Harik et al., 1979a; LaManna et al., 1981). Rats were anesthetized with pentobarbital $(50 \mathrm{mg} / \mathrm{kg}$, i.p.) and the femoral artery and vein were cannulated for monitoring arterial blood pressure, sampling arterial blood gases, and intravenous infusion of supplemental pentobarbital to maintain light anesthesia. Tracheostomy was performed, and the rats were paralyzed with curare and ventilated with a mixture of $30 \% \mathrm{O}_{2}$ and $70 \% \mathrm{~N}_{2}$ with a positive pressure respirator. Tidal volume and respiratory rate were adjusted to maintain blood gas values within the normal range $\left(\mathrm{PaO}_{2}>\right.$ $110 \mathrm{~mm} \mathrm{Hg}, \mathrm{pH} \sim 7.4$, and $\mathrm{PaCO}_{2}=35$ to $40 \mathrm{~mm} \mathrm{Hg}$ ). Body temperature was maintained at $37^{\circ} \mathrm{C}$ by a heating pad. An $8 \times 5 \mathrm{~mm}$ craniotomy was fashioned in the frontoparietal region bilaterally with a dental burr. The dura was left intact. The optical equipment was focused on either the left or right side, alternating from experiment to experiment. A forked stimulating electrode (tips $0.1 \mathrm{~mm}$ in diameter, $0.5 \mathrm{~mm}$ apart) was placed about 1 $\mathrm{mm}$ from a $\mathrm{Ag}-\mathrm{AgCl}_{2}$ recording electrode near the center of the optical fields. The recording electrode monitored both electrocorticogram and DC-coupled surface electrical potential (cortical steady potential) with reference to neck musculature.

Changes in reduction/oxidation (redox) states of cytochrome $c$ oxidase (cytochrome $a a_{3}$ ) signaled the activity of the oxidative metabolic system. These changes were monitored by dual wavelength reflection spectrophotometry (Jöbsis et al., 1977). The procedure is based on the fact that cytochrome $a a_{3}$ absorbs light at $605 \mathrm{~nm}$ more strongly when reduced than when it is oxidized. Light at $605 \mathrm{~nm}$, and at a "reference" wavelength equibestic to hemoglobin volume and oxygenation shifts (590 nm), was supplied to the cortical surface from individual monochromators. Light reflected from the surface was collected by a microscope objective and detected with a photomultiplier tube. The signals, representing the intensity of light reflected at the reference wavelength and the difference between the intensity of light at the sample and reference wavelengths, were displayed on a strip chart recorder. The first of these signals compensated for and provided a useful indicator of blood volume shifts. The difference signal (605 to $590 \mathrm{~nm})$ represented redox shifts of cytochrome $a a_{3}$. These signals were expressed as a percentage of the full scale with limits set between 0 , indicating total darkness, and $100 \%$, indicating the intensity of the reference illumination. Sample light then was adjusted to be equal to the reference intensity.

The cortex was stimulated by electrical pulses applied directly to the exposed dura. The protocol was to apply pulses of $0.5 \mathrm{msec}$ duration at $20 \mathrm{~Hz}$ for $2 \mathrm{sec}$ with increasing stimulus intensity, beginning at $8 \mathrm{~V}$, until a negative shift of the cortical steady potential was observed. Stimulus intensity then was increased to get a range of response amplitudes but with caution to keep stimulus intensity below threshold for provoking spreading cortical depression. Next, this procedure was repeated on the other side of the brain. With few exceptions, cortical stimulation of this type did not result in a change in blood pressure or pulse rate. When such cardiovascular effects were observed, the data were discarded.

At the end of each experiment, the rats were killed by decapitation and cortical tissue samples were obtained for NA assay.

Noradrenaline assay. Tissue samples were weighed in the frozen state and homogenized in $50 \mathrm{vol}$ of ice cold 0.1 $\mathbf{N}$ perchloric acid. Portions of the supernatant were assayed in duplicate for NA by the enzymatic-isotopic method of Henry et al. (1975).

Data analysis. 'Tissue concentrations of NA, results of receptor binding assays, and cyclic AMP generation studies obtained from cerebral cortices ipsilateral to the LC lesion were compared to results obtained from contralateral cortices using the Student's $t$ test (two tailed). Similar comparisons were made between results obtained from either hemisphere of unulaterally lesioned rats and those of controls. Significance was accepted at $p<0.05$.

The oxidative metabolic transients, recorded on strip chart records, were digitized with a data tablet and processed with a Tektronix 4051 graphic system. Compensation for base line drift was provided by normalizing each response to a line derived by linear regression of pre- and post-response data points. The peak amplitude of the transient metabolic response from this base line was termed the $P_{\max }$. The time from the stimulus onset to this peak and the time from the peak to the point midway between peak and base line levels were called $T_{P \max }$ and $T_{1 / 2}$ off, respectively. The ratio of the peak blood volume change to the peak cytochrome oxidase change was termed the $\mathrm{BV} / \mathrm{Cyt}$ ratio. The means for these measurements derived from responses from 6 to 12 stimuli applied to each hemisphere were computed. The descriptive paramelers from each hemisphere ipsilateral to the successful LC lesion were expressed as a percentage of those from the corresponding contralateral hemisphere. The means and standard errors of these percentage changes were derived and compared using a twotailed, non-paired $t$ test. Significance was accepted at $p$ $<0.05$.

\section{Results}

NA depletion following LC lesion. We previously demonstrated that the local infusion of 6-OHDA into the LC 
results in a minimum of $70 \%$ depletion of NA in approximately 80 to $90 \%$ of the rats after 2 weeks. This decline was apparent in comparisons between ipsilateral NAdepleted hemispheres and contralateral hemispheres of unilaterally lesioned rats as well as between ipsilateral hemispheres of lesioned rats and those from controls (Harik et al., 1979a; Sharma et al., 1979, 1981; LaManna et al., 1981). In this study also, $70 \%$ depletion of NA in the ipsilateral cerebral cortex was considered to be the minimum requirement for success of the $\mathrm{LC}$ lesion except in rats studied 1 week after lesion (see "Materials and Methods").

Figure 1 shows the effect of unilateral LC lesion upon NA content of ipsilateral and contralateral cerebral hemispheres when compared to non-lesioned, littermate control rats. In contrast to rapid NA depletion (50\% in 1 day) by intraventricular 6-OHDA (Sporn et al., 1977), selective LC lesion produced $50 \%$ NA depletion in 1 week. However, since data at 1 week may have included some unsuccessful lesions, a slightly greater NA decline is possible than is shown in the figure. LC lesion produced maximum NA depletion of about $90 \%$ in 2 to 4 weeks and this depletion was maintained throughout the 8-week period of this study (Fig. 1). The remaining NA content of the ipsilateral cerebral cortex (about 10\%) probably represents noradrenergic innervation from sources other than the LC since bilateral LC lesion failed to produce complete depletion of cortical NA (Sharma et al., 1981). Hemispheres contralateral to LC lesion were not altered significantly in terms of NA content when compared to controls although there is a tendency for increased NA levels at 4 weeks after LC lesion. The data in Figure $1 A$ were obtained from animals used in the receptor binding studies, while the data in Figure $1 B$ were obtained from rats used in studies of cerebral oxidative metabolism. Despite the different conditions prior to tissue retrieval in these two studies and the fact that the studies were carried out at different times, the effects of LC lesion on cortical NA are very similar.

Adrenergic receptor binding changes following $L C$ lesions. Since postsynaptic receptor regulation is mediated primarily by the availability of transmitter substances at receptor sites, it was important to investigate changes in cortical noradrenergic receptors induced by LC lesion. Unilateral LC lesions did not result in any significant changes in the binding of $\left[{ }^{3} \mathrm{H}\right] \mathrm{WB}-4101$ to $\alpha_{1}$ adrenergic receptors throughout the 8 -week period of this study (Fig. 2).

In contrast, there was a definite increase in the binding of $\left[{ }^{3} \mathrm{H}\right] \mathrm{DHA}$ to $\beta$-adrenergic receptors in the NA-depleted cortex (Fig. 3). Differences in the binding of $\left[{ }^{3} \mathrm{H}\right] \mathrm{DHA}$ were not significantly different at 1 week after the lesion, at a time when NA was not depleted maximally in the ipsilateral hemisphere, but a maximal increase in binding of about $70 \%$ occurred at 2 weeks following LC lesion $(p<0.001)$. This increase in $\left[{ }^{3} \mathrm{H}\right]$ DHA binding was transient and no significant differences were apparent between ipsilateral and contralateral hemispheres 4,5 , and 8 weeks after LC lesion at a time when cerebral NA ipsilateral to the LC lesion continued to be depleted.
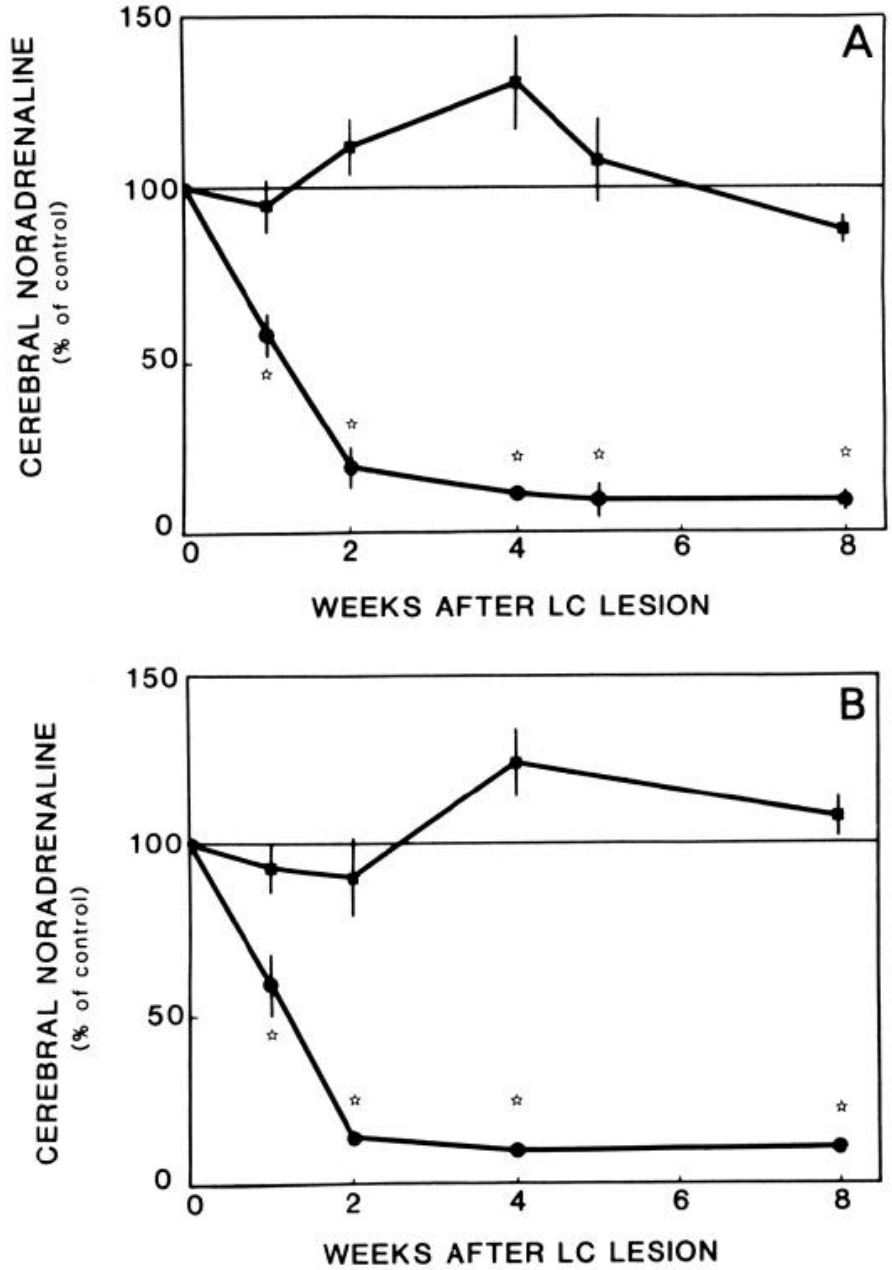

Figure 1. Effect of unilateral LC lesion on tissue NA levels in ipsilateral (circles) and contralateral (squares) cerebral hemispheres. Results obtained from rats used for receptor binding assays $(A)$ and from rats used for studies of cerebral oxidative metabolism $(B)$ are compared. Data points denote mean NA content $( \pm \mathrm{SEM})$ of 6 to 10 rats in each group. The data are expressed as the percentage of the mean of 6 to 10 littermate control rats killed at the same time as the unilateral LC-lesioned animals. The mean NA content of control cortices varied from group to group with a gross average of approximately $300 \mathrm{ng}$ of NA/gm, wet weight, of tissue. Results obtained from rats sacrificed 2 to 8 weeks after LC lesion included only successful lesions (greater than $70 \%$ NA depletion). Results from all rats sacrificed 1 week after LC lesion are included in the data analysis on the assumption that they were all successfully lesioned. NA levels of contralateral hemispheres were not significantly different from control, while those of ipsilateral hemispheres were significantly different at $p<0.001$ (stars).

Changes in isoproterenol-induced cyclic AMP generation following LC lesion. Since isoproterenol-induced cyclic AMP formation is related to $\beta$-adrenergic receptor activity (Sporn et al., 1977; Skolnick et al., 1978; Dolphin et al., 1979), we studied the effect of NA depletion on the isoproterenol-induced cyclic AMP-generating system in brain minces obtained from the two hemispheres of unilateral LC-lesioned rats at 2 and 8 weeks following lesion. These results (Fig. 4) demonstrate the expected increased ability of isoproterenol to generate cyclic AMP in the 


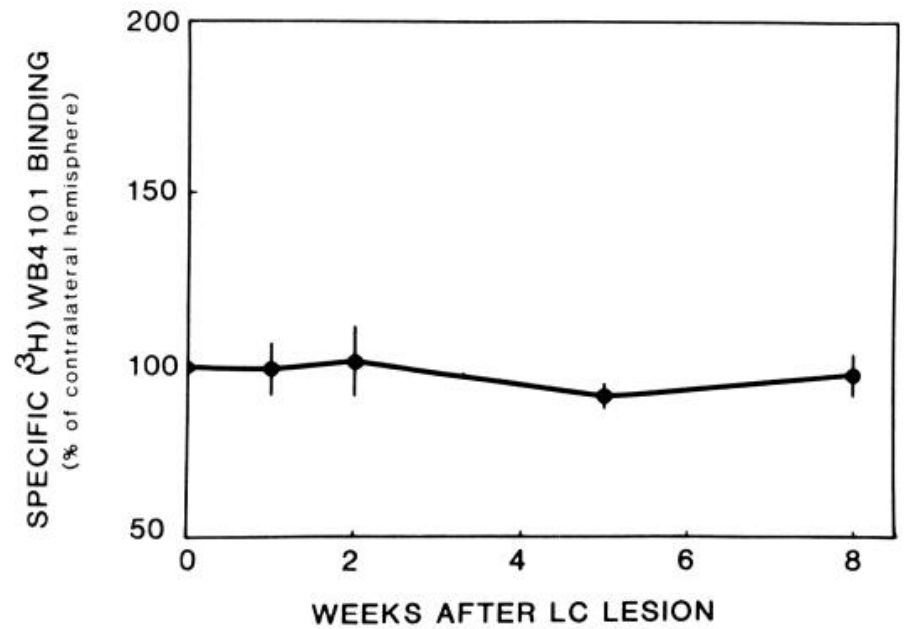

Figure 2. Effect of unilateral LC lesion on the specific binding of $\left[{ }^{3} \mathrm{H}\right] \mathrm{WB}-4101$ to particulate fractions of cerebral hemispheres. Data points represent the means ( \pm SEM) of ipsilateral hemispheres of 6 to 10 rats in each group expressed as a percentage of the specific binding of contralateral hemispheres. The specific binding of control hemispheres was about 100 $\mathrm{fmol} / \mathrm{mg}$ of protein. No significant differences were observed between hemispheres in animals sacrificed 1 to 8 weeks after LC lesion.

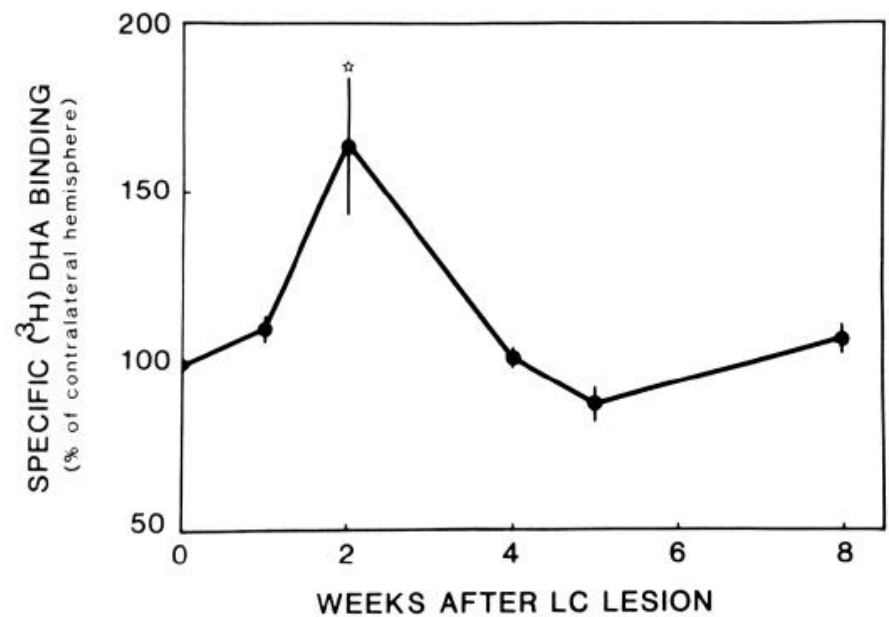

Figure 3. Effect of unilateral LC lesion on the specific binding of $\left[{ }^{3} \mathrm{H}\right] \mathrm{DHA}$ to particulate fractions of cerebral hemispheres. Data points represent the means $( \pm$ SEM) of ipsilateral hemispheres of 6 to 10 rats in each group expressed as a percentage of the specific binding of contralateral hemispheres. The specific binding of control hemispheres was around $60 \mathrm{fmol} / \mathrm{mg}$ of protein. Differences between the two hemispheres were significant only at 2 weeks after LC lesion $(p<0.001 ;$ star $)$.

NA-depleted hemisphere at 2 weeks $(p<0.01)$. However, no significant differences between ipsilateral and contralateral hemispheres were apparent at 8 weeks. The ability of the minces to generate cyclic AMP under basal conditions was similar in both hemispheres at 2 and 8 weeks. Also, there were no differences in cyclic AMP generation between hemispheres contralateral to LC lesion and those of controls under both basal and isoproterenolstimulated conditions.

Changes in oxidative metabolism following LC lesion. The rates of oxidation and subsequent re-reduction of

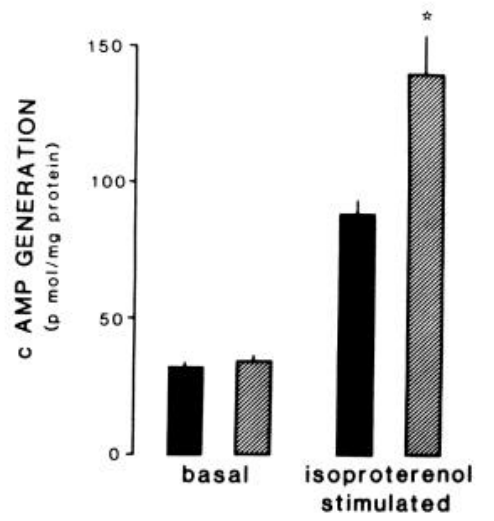

2 WEEKS

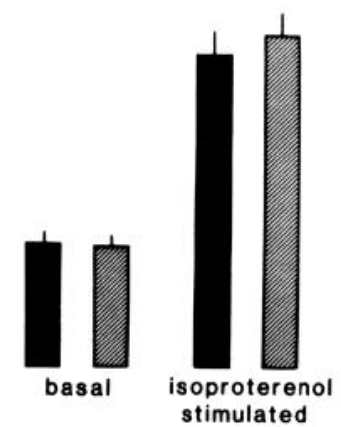

8 WEEKS
Figure 4. Effect of unilateral LC lesion on cyclic AMP generation in cerebral cortical minces under basal conditions and isoproterenol $(0.1 \mathrm{~mm})$ stimulation 2 and 8 weeks after lesion. Data from hemispheres contralateral to the lesion (solid bars) were compared to those from ipsilateral hemispheres (hatched bars). Each bar represents the mean ( \pm SEM) of results obtained from five rats in the 2 -week experiment and nine rats in the 8-week experiment. The NA content of contralateral and ipsilateral hemispheres were $222 \pm 23 \mathrm{ng} / \mathrm{gm}$ and $21 \pm 3 \mathrm{ng} / \mathrm{gm}$ (mean \pm SEM) 2 weeks after lesion and $293 \pm 24 \mathrm{ng} / \mathrm{gm}$ and 39 $\pm 8 \mathrm{ng} / \mathrm{gm} 8$ weeks after lesion. No significant differences between the two hemispheres were detected under basal conditions at 2 or 8 weeks after lesion. With isoproterenol stimulation, there was a significant difference at 2 weeks $(p<0.01$; star) but not at 8 weeks.

cytochrome oxidase following direct cortical stimulation were slowed and the concomitant blood volume increment was attenuated in the NA-depleted hemisphere 2 weeks after LC lesion (Harik et al., 1979a; LaManna et al., 1981). To document the development and persistence of these effects, rats were tested 1 to 8 weeks after unilateral LC lesion. Traces representative of stimulusevoked responses in rats at 2 and 8 weeks following LC lesion are shown in Figure 5. Slowed re-reduction of cytochrome oxidase and attenuated blood volume responses seen at 2 weeks (upper traces) were not observed at 8 weeks (lower traces). Figure 5 also shows a representative response to stimulation of cytochrome oxidase and the terms used for quantitation in Figures 6 to 8 .

The oxidation rate of cytochrome oxidase following stimulation is compared at several times following LC lesion in Figure 6. Two weeks after lesion, the time to peak oxidation was increased significantly on the lesioned side $(p<0.05)$. There were no differences between hemispheres at 1,4 , and 8 weeks after lesion.

Figure 7 shows the effects of NA depletion on the rate of re-reduction of cytochrome oxidase after stimulation. The rate of recovery on the lesion side was slowed by more than $50 \%$ only at 2 weeks after LC lesion $(p<0.05)$. The slowed recovery on the lesioned side was not apparent at 1,4 , and 8 weeks after lesion.

Figure 8 shows that the ratio of the increase in blood volume and the amplitude of oxidation of cytochrome $a a_{3}$ (BV/Cyt) was decreased significantly on the lesion side 2 weeks following LC lesion $(p<0.05)$. This ratio 


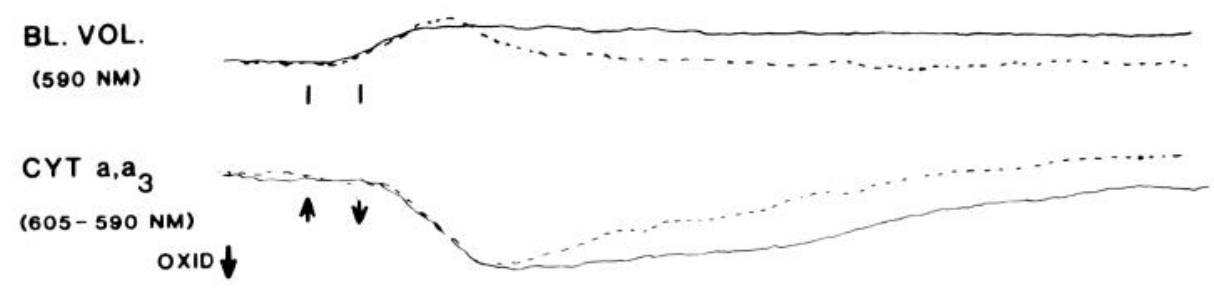

8 WEEKS AFTER LC LESION

BL. VOL.

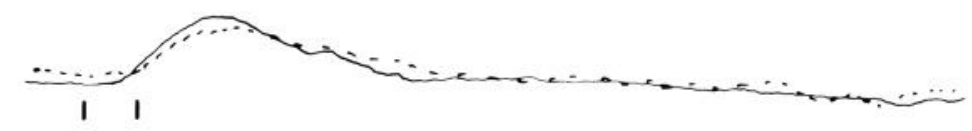

CYT $a, a_{3}$
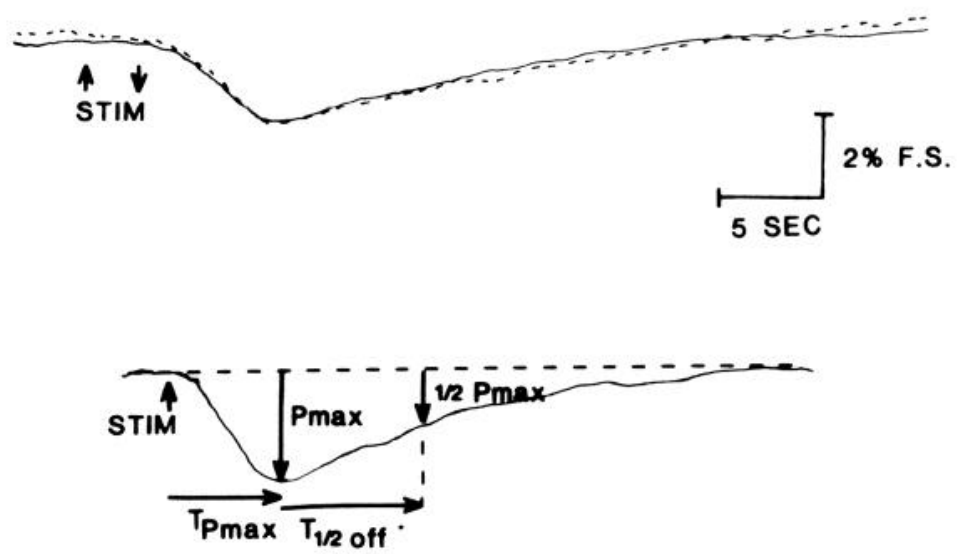

Figure 5. Optical responses to direct cortical stimulation from hemispheres ipsilateral (solid lines) and contralateral (dashed lines) to unilateral LC lesion. Upper traces represent responses recorded 2 weeks after lesion $(\mathrm{NA}=36 \mathrm{ng} / \mathrm{gm}$ on ipsilateral (left) hemisphere and $324 \mathrm{ng} / \mathrm{gm}$ on the contralateral hemisphere). Lower traces represent responses recorded 8 weeks after LC lesion $(\mathrm{NA}=60 \mathrm{ng} / \mathrm{gm}$ on the ipsilateral (left) hemisphere and $295 \mathrm{ng} / \mathrm{gm}$ on the contralateral hemisphere). Also shown is a typical cytochrome response with the amplitude and kinetic parameters defined. The abbreviations used are: BL VOL, blood volume; CYT a, $\mathrm{a}_{3}$, cytochrome $a a_{3}$; STIM, stimulation; F.S., full scale.

was not altered 1 week after lesion and returned to control values at 4 and 8 weeks after lesion.

\section{Discussion}

These investigations demonstrate that changes in in vivo oxidative metabolic activity and in vitro receptor binding and cyclic AMP generation, apparent in cerebral cortices 2 weeks after LC lesion, are reversible, and the appearance and disappearance of these abnormalities are related temporally. Such recovery occurred despite the continued depletion of cerebral NA. These data strongly suggest that compensatory mechanisms of the brain are capable of meeting the challenge posed by LC lesion and lead to speculation that there may be a causal relationship among the parameters studied.

The experimental paradigm of this investigation offered several advantages. The LC on one side was specifically lesioned, thus avoiding inadvertent injury to neighboring regions and depletion of other monoaminergic systems. Also, the non-lesioned side acted as an internal control. This is based on the uncrossed ipsilateral ceruleocortical connections which supply most of the NA innervation to the cerebral cortex (Kobayashi et al., 1975). Another advantage was that the effects of NA depletion were considered for a prolonged period. Finally, in vitro and in vivo studies could be correlated in parallel in the same animal model.

Reports of increased cerebral $\beta$-adrenergic receptor density (Sporn et al., 1977; Dolphin et al., 1979) and increased isoproterenol-induced cyclic AMP generation (Dismukes et al., 1975; Sporn et al., 1977; Skolnick et al., 1978; Dolphin et al., 1979) following NA depletion have been considered evidence for denervation supersensitivity. In our laboratory, NA depletion by LC lesion or by chronic reserpine treatment also produced increased density of $\beta$-adrenergic receptors (Sharma et al., 1981). However, $\alpha$-adrenergic receptors, whether in the cerebral cortex, hippocampus, or cerebellum, were not increased 


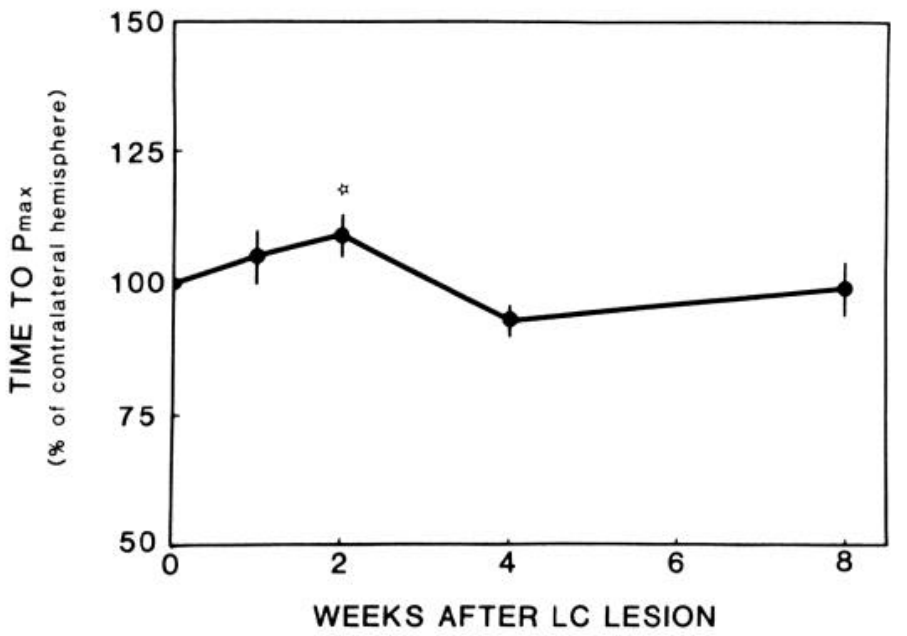

Figure 6. Effect of unilateral LC lesion on the rate of oxidation (Time to $P_{\max }$ ) of cytochrome $a a_{3}$ after direct cortical stimulation. Response times from ipsilateral hemispheres are presented as a percentage of those of the contralateral hemispheres. Time after LC lesion is depicted on the abscissa. Each data point represents the mean $( \pm \mathrm{SEM})$ of 6 to 10 rats. Only at 2 weeks after LC lesion was the time to $P_{\max }$ significantly prolonged $(p<0.05 ;$ star $)$.

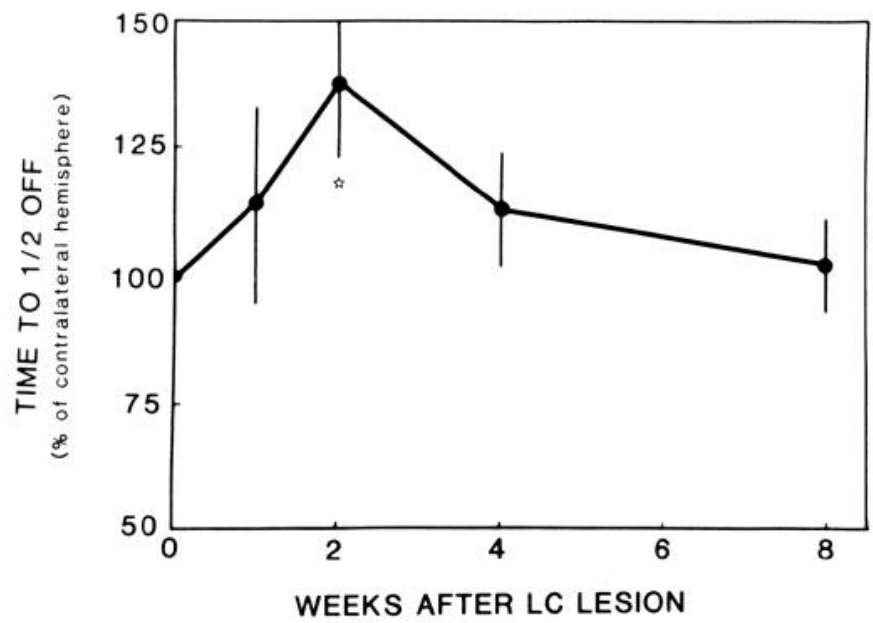

Figure 7. Effect of unilateral LC lesion on the rate of rereduction (Time to $1 / 2$ off) of cytochrome $a a_{3}$ after direct cortical stimulation. Response times from ipsilateral hemispheres are presented as a percentage of those of the contralateral hemispheres. Time after LC lesion is depicted on the abscissa. Each data point represents the mean ( \pm SEM) of 6 to 10 rats. Only at 2 weeks after LC lesion was the re-reduction rate of cytochrome oxidase significantly prolonged $(p<0.05 ;$ star $)$.

(Sharma et al., 1979, 1981). This lack of change in $\alpha$ adrenergic receptors agrees with Skolnick et al. (1978) but is at variance with U'Prichard and Snyder (1978) and U'Prichard et al. (1979). This discrepancy could be due to the late development of $\alpha$-adrenergic receptor supersensitivity, which may have been missed in our short term studies. Therefore, we studied noradrenergic receptor binding 1 to 8 weeks after LC lesion. Despite continued NA depletion, we were unable to detect increased $\alpha$-adrenergic receptor binding (Fig. 2).

A most interesting feature of this prolonged study is the observation that increased $\beta$-adrenergic receptor

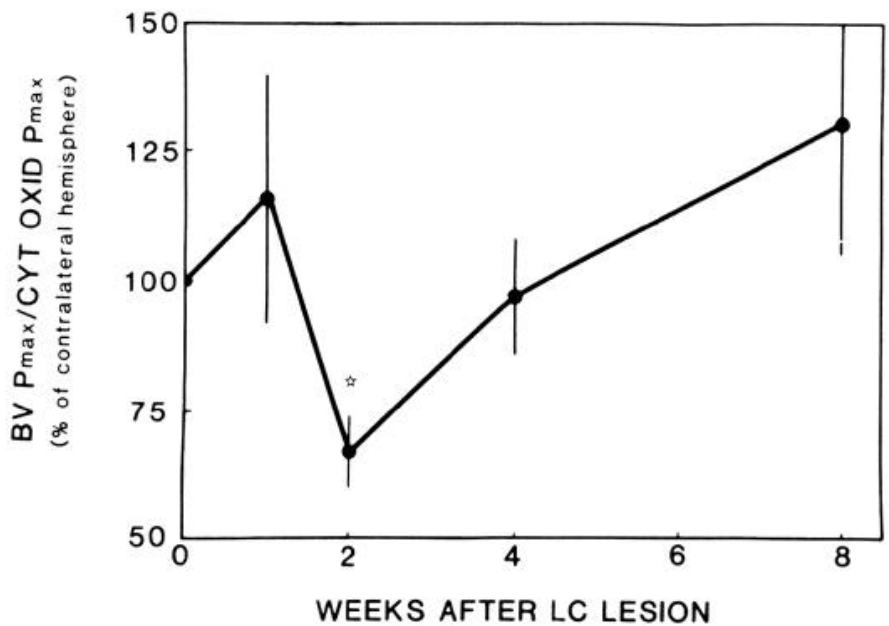

Figure 8. Effect of unilateral LC lesion on the ratio of blood volume (BV) increase to cytochrome $a a_{3}$ oxidation (CYT OXID) after direct cortical stimulation. BV/Cyt ratios from ipsilateral hemispheres are expressed as a percentage of those of the contralateral hemispheres. These percentages are depicted on the graph as the means $( \pm$ SEM) of 6 to 10 animals at each time point following lesion. Only at 2 weeks after LC lesion was the BV/Cyt ratio significantly different $(p<0.05$; star).

binding, documented at 2 weeks after LC lesion, returned to base line values by 4 weeks (Fig. 3). Thus, denervation supersensitivity appears to be both selective and reversible.

As the density of $\beta$-adrenergic receptors returned to control despite continued NA depletion, the receptorlinked, isoproterenol-induced adenylate cyclase hyperactivity also returned to control (Fig. 4).

In vivo studies demonstrate that LC lesion results in slowed rates of oxidation and re-reduction of cytochrome $a a_{3}$ and a concomitant decrease in blood volume response to increased metabolic demand. These abnormalities were apparent only 2 weeks after LC lesion. Recovery occurred by 4 weeks. The several possibilities that could account for these changes include substrate limitation, abnormality of vascular reactivity, altered ion transport, or uncoupling of oxidative phosphorylation. Uncoupling is unlikely because the steady state ratio is not different in NA-depleted and control hemispheres (LaManna et al., 1981). Altered $\mathrm{K}^{+}$transport is discounted by the findings of Sick et al. (1981) that the rate of extracellular $\mathrm{K}^{+}$decline after stimulation is unchanged in the hemisphere ipsilateral to LC lesion. It is our belief that prolonged oxidation of cytochrome $a a_{3} 2$ weeks after LC lesion is due to transient limitation of substrate and/or circulatory perfusion. Deficiency of circulation is supported by the attenuated blood volume response to stimulation as well as the slowed rate of oxidation $\left(T_{P \max }\right)$ which could be due to limited delivery of $\mathrm{O}_{2}$.

Recovery of metabolic and blood volume responses occurred in a similar time period as $\beta$-adrenergic receptor binding and cyclic AMP generation. This suggests that $\beta$ receptor action is linked to the responses to cerebral evoked potential activity of cytochrome oxidase and blood volume. This could occur through $\beta$ receptor mediation of increased substrate availability by an action on glycolytic enzymes or by $\beta$-adrenergic control of cere- 
bral circulation. The latter is supported by recent demonstrations of $\beta$-adrenergic receptors on cerebral microvessels (Harik et al., 1980; Peroutka et al., 1980). However, the possibility exists that these changes may be epiphenomena of LC lesion and NA depletion.

There are several possible explanations of the cerebral compensation for prolonged NA depletion. Among these is regeneration of noradrenergic ceruleocortical connections. Previous work has documented regeneration of noradrenergic systems after intracisternal (Nygren and Olson, 1976) and intraspinal (Nygren et al., 1971) injection of 6-OHDA. However, regeneration is an unlikely explanation of our results for the following reasuns: (1) In this study, NA remained depleted in the ipsilateral cercbral cortex for 8 weeks, while regeneration has been associated with a return of tissue NA content (Björklund and Lindvall, 1979). (2) Preliminary work (W. J. Logan and $\mathrm{S}$. I. Harik, manuscript in preparation) suggests that the high affinity uptake of NA into homogenates of the ipsilateral cerebral cortex is decreased markedly 2 weeks after LC lesion and does not recover by 8 weeks. High affinity uptake of NA, a marker of NA neuronal elements, returned to normal in regeneration after chemical NA axotomy (Björklund and Lindvall, 1979). (3) Regeneration has not been described after NA cell bodies have been superfused with high local concentrations of 6 OHDA. Regeneration of monoaminergic systems after chemical lesions occurred when chemical toxins were injected into the cerebrospinal fluid or into axonal tracts, thus destroying mostly synaptic terminals and axons but sparing neuronal cell bodies (Thoenen and Tranzer, 1973).

Another possible compensatory mechanism could be proliferation of nerve endings of other catecholaminergic systems to occupy synaptic spaces vacated by the degenerating LC terminals. This possibility is based on the fact that recovery of $\beta$-adrenergic receptors and increased cyclic AMP generation did not occur 40 days after intraventricular 6-OHDA (Sporn et al., 1977). Such treatment is known to produce widespread destruction of noradrenergic, dopaminergic, and some serotonergic systems (Thoenen and Tranzer, 1973). The possibility of such proliferation, however, requires further investigation before it can be accepted.

Irrespective of the underlying mechanism through which recovery is effected, the reversible effects of LC lesion and NA depletion on rat cerebral cortex underscore the importance of the adaptive capabilities of the central nervous system. Indeed, it could be used to study the phenomena of plasticity, regeneration, and sprouting in the adult mammalian brain. These investigations also emphasize the importance of the time variable that elapses between a lesion and the study of its effects.

\section{References}

Berg, D. K., P. B. Kelly, P. B. Sargent, P. Williamson, and Z. W. Hall (1972) Binding of alpha-bungarotoxin to acetylcholine receptors in mammalian muscle. Proc. Natl. Acad. Sci. U. S. A. 69: 147-151.

Björklund, A., and O. Lindvall (1979) Regeneration of normal terminal innervation patterns by central noradrenergic neurons after 5,7-dihydroxytryptamine-induced axotomy in the adult rat brain. Brain Res. 171: 271-293.
Bylund, D. B., and S. H. Snyder (1976) Beta adrenergic receptor binding in membrane preparations from mammalian brain. Mol. Pharmacol. 12: 568-580.

Cannon, W. B., and A. Rosenblueth (1949) The Supersensitivity of Denervated Structures, Macmillan, New York.

Dismukes, R. K., P. Ghosh, C. R. Creveling, and J. W. Daly (1975) Altered responsiveness of adenosine $3^{\prime}: 5^{\prime}$-monophosphate-generating systems in rat cortical slices after lesions of the medial forebrain bundle. Exp. Neurol. 49: 725-735.

Dismukes, R. K., P. Ghosh, C. R. Creveling, and J. W. Daly (1976) Norepinephrine depletion and responsiveness of norepinephrine-sensitive cAMP generating systems in guinea pig brain. Exp. Neurol. 52: 206-215.

Dolphin, A., J. Adrien, M. Hanon, and J. Bockaert (1979) Identity of $\left[{ }^{3} \mathrm{H}\right]$ dihydroalprenolol binding sites and beta-adrenergic receptor coupled with adenylate cyclase in the central nervous system: Pharmacological properties, distribution and adaptive responsiveness. Mol. Pharmacol. 15: 1-15.

Gilman, A. G. (1970) A protein binding assay for adenosine $3^{\prime}$ $5^{\prime}$-cyclic monophosphate. Proc. Natl. Acad. Sci. U. S. A. 67: 305-312.

Greenberg, D. A., D. C. U'Prichard, and S. H. Snyder (1976) Alpha noradrenergic receptor binding in mammalian brain: Differential labeling of agonist and antagonist states. Life Sci. 19: $69-76$.

Harik, S. I., J. C. LaManna, A. I. Light, and M. Rosenthal (1979a) Cerebral norepinephrine: Influence on cortical oxidative metabolism in situ. Science 206: 69-71.

Harik, S. I., J. C. LaManna, M. Rosenthal, and S. P. Banerjee (1979b) Locus coeruleus lesions: Effects on cerebral oxidative metabolism in vivo. III. Acute and chronic changes in relation to adrenergic receptors. Soc. Neurosci. Abstr. 5: 336.

Harik, S. I., V. K. Sharma, J. R. Wetherbee, R. H. Warren, and S. P. Banerjee (1980) Adrenergic receptors of cerebral microvessels. Eur. J. Pharmacol. 61: 207-208.

Henry, D. P., B. J. Starman, D. G. Johnson, and R. H. Williams (1975) A sensitive radioenzymatic assay for norepinephrine in tissue and plasma. Life Sci. 16: 375-384.

Jöbsis, F. F., J. Keizer, J. C. LaManna, and M. Rosenthal (1977) Reflectance spectrophotometry of cytochrome $a, a_{3}$ in vivo. J. Appl. Physiol. 43: 858-872.

Jonsson, G., and H. Hallman (1978) Changes in beta-receptor binding sites in rat brain after neonatal 6-hydroxydopamine treatment. Neurosci. Lett. 9: 27-32.

Kobayashi, R. M., M. Palkovits, D. M. Jacobowitz, and I. J. Kopin (1975) Biochemical mapping of the noradrenergic projection from the locus ceruleus. Neurology (N. Y.) 25: 223233.

LaManna, J. C., S. I. Harik, A. I. Light, and M. Rosenthal (1981) Norepinephrine depletion alters cerebral oxidative metabolism in the "active" state. Brain Res. 204: 87-101.

Lowry, O. H., N. .J. Rosebrough, A. L. Farr, and R. J. Randall (1951) Protein measurement with the Folin phenol reagent. J. Biol. Chem. 193: 265-275.

Miledi, R., and L. T. Potter (1971) Acetylcholine receptors in muscle fibers. Nature 233: 599-603.

Nygren, L. -G., and L. Olson (1976) On spinal noradrenaline receptor supersensitivity: Correlation between nerve terminal densities and flexor reflexes at various times after intracisternal 6-hydroxydopamine. Brain Res. 116: 455-470.

Nygren, L. -G., L. Olson, and A. Seiger (1971) Regeneration of monoamine-containing axons in the developing and adult spinal cord of the rat following intraspinal 6-OH-dopamine injections or transections. Histochemie 28: 1-15.

Palmer, C. G., F. Sulser, and G. A. Robinson (1973) Effects of neurohumoral and adrenergic agents on cyclic AMP levels in various areas of rat brain in vitro. Neuropharmacology 12 : $327-337$. 
Peroutka, S. J., M. A. Moskowitz, J. F. Reinhard, Jr., and S. H. Snyder (1980) Neurotransmitter receptor binding in bovine cerebral microvessels. Science 208: 610-612.

Pointon, S. E., and S. P. Banerjee (1979) Alpha- and betaadrenergic receptors of the rat salivary gland: Elevation after chemical sympathectomy. Biochim. Biophys. Acta 584: 231241.

Sharma, V. K., S. I. Harik, M. Ganapathi, R. Busto, and S. P. Banerjee (1979) Locus ceruleus lesion and chronic reserpine treatment: Effect on adrenergic and cholinergic receptors in cerebral cortex hippocampus. Exp. Neurol. 65: 685-690.

Sharma, V. K., S. I. Harik, R. Busto, and S. P. Banerjee (1981) Effects of noradrenaline depletion on adrenergic and muscarinic cholinergic receptors in the cerebral cortex, hippocampus and cerebellum. Exp. Neurol., in press.

Sick, T. J., S. I. Harik, J. C. LaManna, and M. Rosenthal (1981) Effect of norepinephrine depletion on potassium transport in cerebral cortex. Trans. Am. Neurol. Assoc., in press.

Skolnick, P., I. P. Stalvey, J. W. Daly, E. Hoyler, and J. N. Davis (1978) Binding of alpha and beta adrenergic ligands to cerebral cortical membranes: Effect of 6-hydroxydopamine treatment and relationship to the responsiveness of cyclic
AMP generating systems in two rat strains. Eur. J. Pharmacol. 47: 201-210.

Sporn, J. R., B. B. Wolfe, T. K. Harden, T. Kendall, and P. B. Molinoff (1977) Supersensitivity in rat cerebral cortex: Preand post-synaptic effects of 6-hydroxydopamine at noradrenergic synapses. Mol. Pharmacol. 13: 1170-1180.

Thoenen, H., and J. P. Tranzer (1973) Pharmacology of 6hydroxydopamine. Annu. Rev. Pharmacol. 13: 169-180.

Trendelenburg, U. (1966) Mechanisms of supersensitivity and subsensitivity to sympathomimetic amines. Pharmacol. Rev. 18: 629-649.

U'Prichard, D. C., and S. H. Snyder (1978) ${ }^{3}$ H-Catecholamine binding to alpha receptors in rat brain: Enhancement by reserpine. Eur. J. Pharmacol. 51: 145-155.

U'Prichard, D. C., D. A. Greenberg, and S. H. Snyder (1977) Binding characteristics of a radiolabeled agonist and antagonist at central nervous system alpha-noradrenergic receptors. Mol. Pharmacol. 13: 454-473.

U'Prichard, D. C., W. D. Bechtel, B. M. Rouot, and S. H. Snyder (1979) Multiple apparent alpha-noradrenergic receptor binding sites in rat brain: Effect of 6-hydroxydopamine. Mol. Pharmacol. 16: 47-60. 